\title{
Acceso vascular único en intervencionismo coronario protegido con dispositivo de asistencia mecánica ventricular
}

\section{Single vascular access in coronary intervention protected with a ventricular mechanical assist device}

\author{
Pablo Salinas*, Fernando Macaya y Antonio Fernández-Ortiz \\ Servicio de Cardiología, Hospital Clínico San Carlos e Instituto de Investigación Sanitaria del Hospital Clínico San Carlos (IdISSC), Madrid, España
}

El dispositivo de asistencia mecánica Impella CP (Abiomed, Danvers, Massachussetts) es el más utilizado para el apoyo hemodinámico en el intervencionismo coronario percutáneo de alto riesgo. Si se desea evitar un acceso adicional radial o femoral, es posible usar el introductor $14 \mathrm{~F}$ del dispositivo de asistencia como acceso vascular único. Este introductor admite el cuerpo del dispositivo de asistencia $9 \mathrm{~F}$ (Fig. 1A, catéter blanco) y un introductor mallado hidrofílico $7 \mathrm{~F}$ (Fig. 1A, catéter verde). Después de implantar de forma habitual el Impella CP se punciona la válvula hemostática en los cuadrantes superiores (Fig. 1B, *) y se evita el catéter de asistencia (Fig. 1B, \#) con una cánula venosa $18 \mathrm{G}$ que permite el paso de una guía de 0.035" (Fig. 1C). A través de la guía se avanza el introductor que hace posible realizar el intervencionismo con catéteres coronarios convencionales 6 o $7 \mathrm{~F}$. Al final del procedimiento se puede retirar el introductor sin sangrado (Fig. 1D) y extraer o mantener el dispositivo de asistencia, según sea conveniente. Aunque se pueden emplear otros introductores, el introductor mallado e hidrofílico de $45 \mathrm{~cm}$ es muy recomendable para reducir la fricción e interacción con el catéter de asistencia. La sencilla técnica de punción de la válvula del introductor $14 \mathrm{~F}$, que describió Jason Wollmuth ${ }^{1}$ de forma original con cánula $21 \mathrm{G}$, se muestra paso a paso en el video complementario.

\section{Financiamiento}

Ninguno.

\section{Conflicto de intereses}

Ninguno.

\section{Responsabilidades éticas}

Protección de personas y animales. Los autores declaran que para esta investigación no se han realizado experimentos en seres humanos ni en animales.

Confidencialidad de los datos. Los autores declaran que en este artículo no aparecen datos de pacientes.

Derecho a la privacidad y consentimiento informado. Los autores declaran que en este artículo no aparecen datos de pacientes.
Correspondencia:

*Pablo Salinas

E-mail: salinas.pablo@gmail.com
Disponible en internet: $14-12-2020$ Arch Cardiol Mex. 2021;91(3):369-370 www.archivoscardiologia.com 1405-9940 / @ 2020 Instituto Nacional de Cardiología Ignacio Chávez. Publicado por Permanyer. Este es un artículo open access bajo la licencia CC BY-NC-ND (http://creativecommons.org/licenses/by-nc-nd/4.0/). 


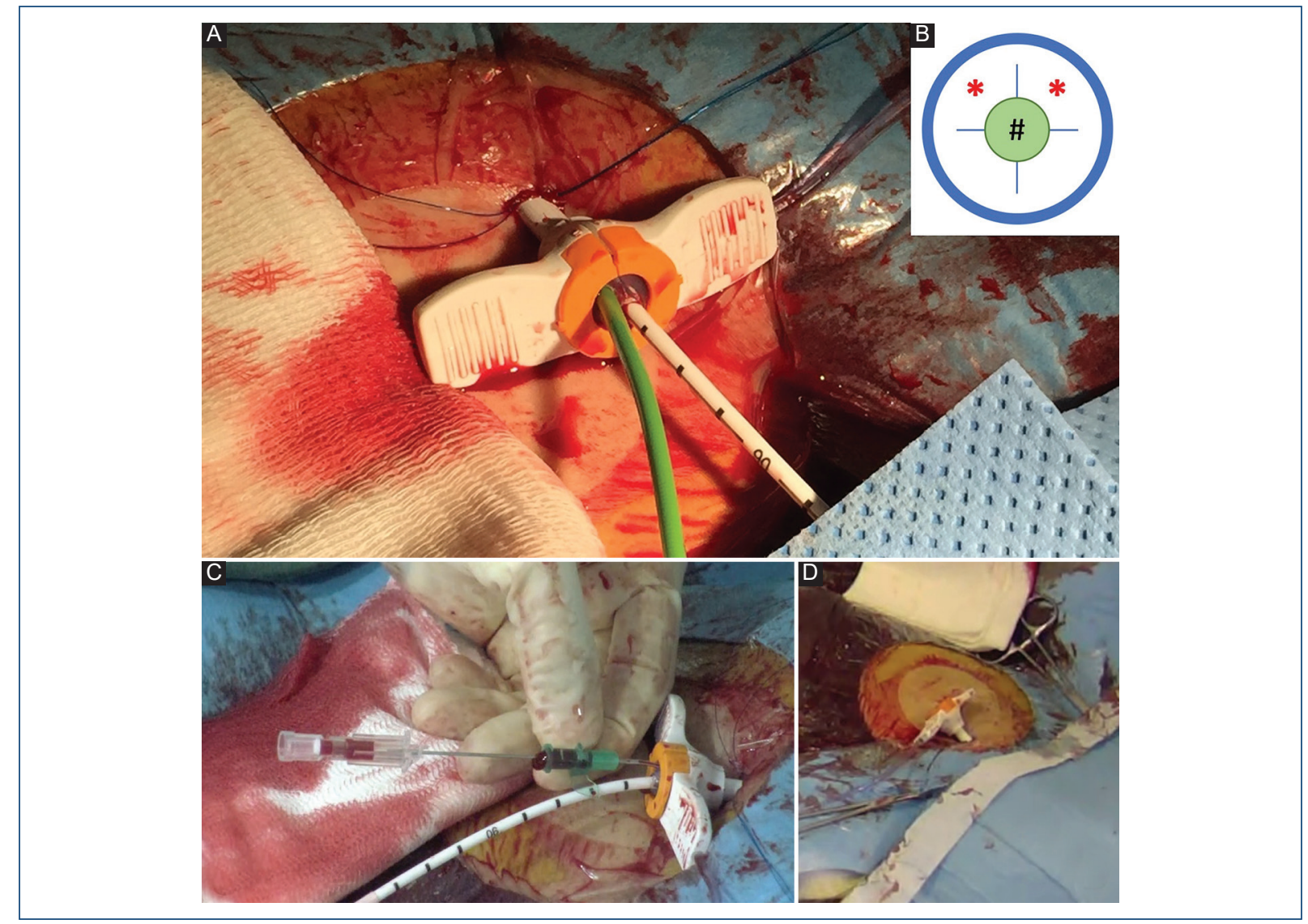

Figura 1. Acceso vascular único en intervencionismo coronario protegido con dispositivo de asistencia mecánica ventricular. A: Posición relativa de catéter de Impella (blanco, 9F) e introductor mallado (verde, 7F). B: Esquema mostrando zonas de punción de la válvula hemostática $\left({ }^{*}\right)$. C: Punción con cánula venosa 18 G. D: Válvula competente tras retirada de introductor mallado.

\section{Bibliografía}

1. Wollmuth J, Korngold E, Croce K, Pinto DS. The single-access for hi-risk $\mathrm{PCl}$ (SHiP) technique. Catheter Cardiovasc Interv. 2020;96(1):114-116. 